\title{
Comparative evaluation of effects of various sealer placement techniques on sealing ability.
}

\author{
Dr. Sukriti Tiwari, Dr. Pradnya Nikhade, Dr. Manoj Chandak \\ (Dept.of Conservative Dentistry, Sharad Pawar Dental College, Wardha, India)
}

\section{Introduction}

Root canal therapy is mainly used to prevent and treat periradicular inflammation by the elimination of microorganisms from the root canal system. The most commonly used methods for microbial control include instrumentation, antimicrobial irrigation, intracanaldressing, adequate filling and coronal restoration.

The root-canal system is usually obturated with gutta-percha combined with a sealer. The long-lasting seal of a root-canal filling, which is of clinical importance, depends largely on the sealing ability of the sealer used because gutta-percha is considered to be impermeable.

Leakage of sealers has often been studied by means of dye penetration, a method in which the specimen has to be destroyed and cannot be used for longitudinal sectioning.

An endodontic sealer plays an important role in successful endodontic treatment. It provides an impervious seal, fills the irregularities and minor discrepancies between the root canal wall and core filling material, and assists in microbial control if microorganisms were left on the root canal walls or in the tubules.

Ideally, a thin layer of the sealer should be evenly applied to canal walls prior to the placement of the core filling material. The thickness of the endodontic sealer layer is very influential in the quality of the root canal filling.

An inadequate sealer coating may result in voids and permit bacterial microleakage which leads to endodontic failure. On the other hand, excess placement of the sealer can result in its extrusion beyond the apical foramen which can prevent or delay healing.[ Moreover, most sealers dissolve over time and the dissolution is probably responsible for the increase in leakage along the root fillings over time.

Therefore, the amount of sealer should be kept to a minimum and should only be found in a thin layer between the gutta-percha and the wall of the canal.

Several techniques of sealer placement have been described in the literature, such as the use of a file, lentulo spiral, absorbent paper point, gutta-percha cone, and an ultrasonic file. Each technique may produce different distribution of the sealer onto the canal walls, which may affect the sealing. At present, there is no evidence to suggest that one method is better and reliable than others.

Hence, the purpose of this study was to evaluate the influence of four most commonly used methods of sealer placement on the sealing ability of the sealer.

\section{Materials And Methods}

30 Freshly extracted mandibular premolars will be stored in $0.9 \%$ saline solution until use. The crown of the teeth atCEJ will be removed using Diamond disc under water coolant. The working length of each group will be determined with $\# 10 \mathrm{k}$-file. The root canals will be prepared upto apical size 30 with F3 protaper file. Between each filling $2 \mathrm{ml}$ of $5.25 \% \mathrm{NaOCl}$ solution will used for irrigation with $2 \mathrm{ml}$ of saline solution. Samples will be divided into 5 Groups.

Root canal obturation will be performed using the single cone obturarion technique. Excess gutta purcha will be removed with a heated instrument and the remaining will be condensed vertically with a cold plugger. All teeth will be radiographed to assess the quality of the root canal filling. The teeth will be stored in $100 \%$ humidity at $370 \mathrm{C}$ for 7 days to allow the sealer to set completely. After 7 days the external root surfaces were coated by two layers of nail polish. In the control group no sealer will be used and the nail polish will apply as experimental group. Each tooth will be subsequently immersed in aqueous solution of $2 \%$ methylene blue dye with $\mathrm{pH} 7.0$ in an individual container and kept in the incubator at $370 \mathrm{C}$ for 3 days. The specimen will then decalcified in 5\% nitric acid for $72 \mathrm{~h}$ and gradually in ascending concentrations of alcohol to $100 \%$ methyl salicylate will be used overnight to clear the teeth. Each tooth will be sectioned longitudinally by using a Diamond disc. all teeth will be examined under in 20x magnification light microscop and statistical analysis will be done using ANOVA test.

\begin{tabular}{l|l|ll}
\hline Group & No of Teeth & Method of Placement \\
\hline
\end{tabular}


Comparative evaluation of effects of various sealer placement techniques on sealing ability.

\begin{tabular}{|l|l|l|}
\hline Group 1 & 6 & k file \\
\hline Group3- & 6 & rotary lentulo spiral \\
\hline Group4- & 6 & Manual lentulo spiral \\
\hline Group 5- & 6 & Master gutta purcha \\
\hline Group 2( control) & 6 & no sealer placed \\
\hline
\end{tabular}

III. Results-

Observation-

K-File

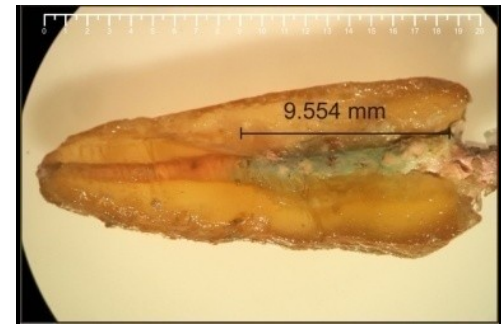

Manual Lentulo

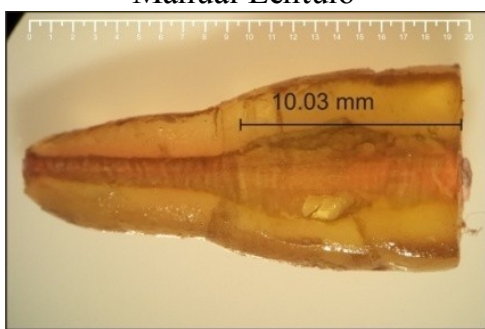

Rotary Lentulo

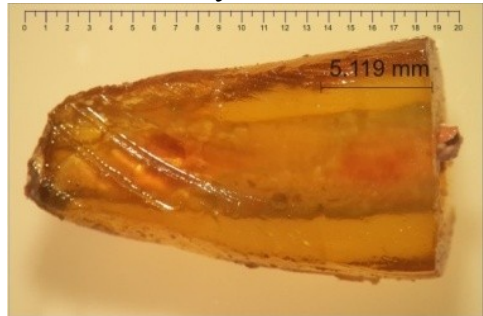

G.P. Points

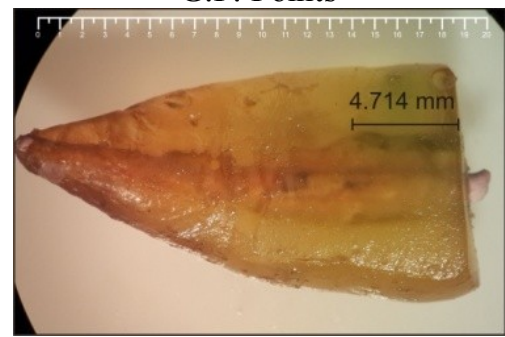

IV. Observations And Results

Table 1: Comparison of different sealer placement techniques Descriptive Statistics

\begin{tabular}{|c|c|c|c|c|c|c|c|c|}
\hline \multirow{2}{*}{ Group } & \multirow{2}{*}{$\mathrm{N}$} & \multirow{2}{*}{ Mean } & \multirow{2}{*}{ Std. Deviation } & \multirow{2}{*}{ Std. Error } & \multicolumn{2}{|c|}{$\begin{array}{l}95 \% \text { Confidence } \\
\text { Interval for Mean }\end{array}$} & \multirow{2}{*}{ Minimum } & \multirow{2}{*}{ Maximum } \\
\hline & & & & & $\begin{array}{l}\text { Lower } \\
\text { Bound } \\
\end{array}$ & \begin{tabular}{|l|l|} 
Upper \\
Bound
\end{tabular} & & \\
\hline \begin{tabular}{|l|} 
Rotary \\
Lentulo
\end{tabular} & 5 & 5.07 & 0.04 & 0.02 & 5.01 & 5.13 & 5.01 & 5.12 \\
\hline $\begin{array}{l}\text { Manual } \\
\text { Lentulo }\end{array}$ & 5 & 10.92 & 0.89 & 0.39 & 9.80 & 12.03 & 10.03 & 12.19 \\
\hline G.P. Points & 5 & 5.55 & 0.16 & 0.07 & 5.35 & 5.76 & 5.30 & 5.74 \\
\hline K-File & 5 & 9.62 & 0.29 & 0.13 & 9.25 & 9.98 & 9.35 & 10.10 \\
\hline Control Grou & 5 & 19.00 & 0.00 & 0.00 & 19.00 & 19.00 & 19.00 & 19.00 \\
\hline
\end{tabular}

Graph 1: Comparison of different sealer placement techniques 


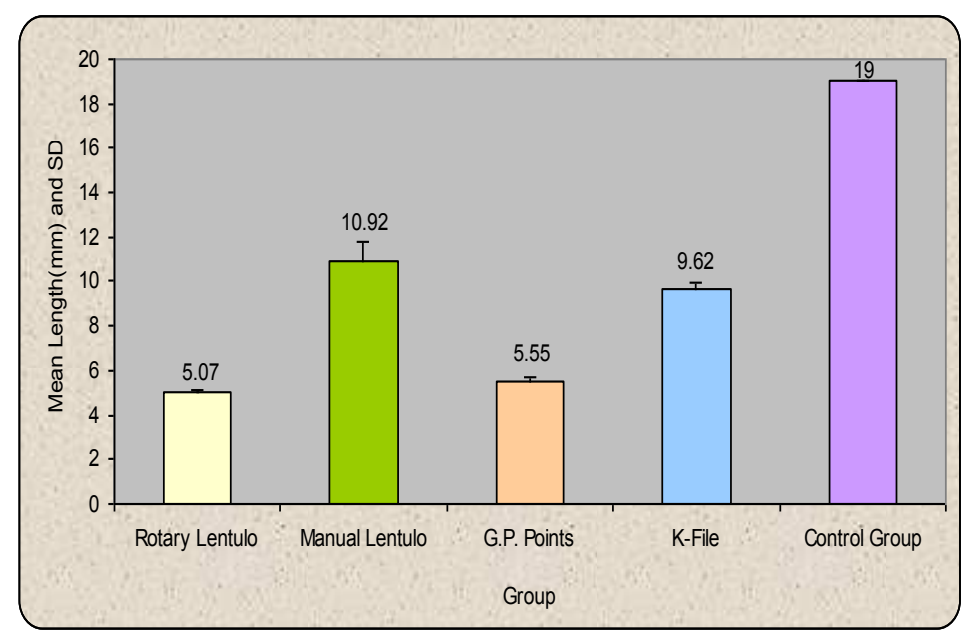

\section{Discussion}

One of the objectives of root canal treatment is to provide a hermetic seal of root canal space. This seal is usually produced by using a semisolid or solid core material in a combination with the endodontic sealer. A solid core cannot produce the desired hermetic seal; thus, the endodontic sealer is required to provide threedimensional obturation.

The experimental system of this study was tested by Using positive control. These specimens showed total dye penetration throughout the root canal, which indicated that it is absolutely necessary to use a sealer to fill voids and gaps between the core material and the root canal walls and further confirmed the fact that filling the root canal with only the core obturating material a sealer resulted in an increased leakage.

The results of this study showed statistically significant difference $(\mathrm{P}=0$. $)$ in microleakage among the four different tested techniques of sealer placement. However, the rotary lentulo spiral group produced the highest value of microleakage and the master gutta-percha coating group had the smallest mean microleakage value.

It was expected that the rotary lentulo spiral group will produce a better adaptation of the sealer onto the canal walls with even thickness which in turn leads to a better seal but the results of this study did not support our assumption. This may be attributed to several factors.

First, more amount of sealer was introduced into the canal as compared with other techniques, and as the sealer shrunk during setting, more gaps and voids might have been created that had contributed to the highest value of microleakage.

Second, a high volume of the sealer material may also interfere with the placement of additional accessory points which leads to less gutta-percha volume percentage compared to the amount of sealer

Third, the use of rotary lentulo spiral during sealer placement may force some air bubbles into the material that will lead to void formation and microleakage, whereas, the endodontic sealer coating of master gutta-percha cone produced less sealer thickness with less potential void formation compared to the other techniques that eventually might have contributed to the smallest microleakage value obtained by this group

Our results are in accordance with Wiemann et al.'s, who compared the influence of four methods, file, lentulo spiral, ultrasonic files, and master gutta-percha, of sealer placement on the sealer sealing ability. The authors found no statistically significant differences among the four groups.

In addition, they reported that less sealer was present in the apical third compared to the coronal and middle thirds of the root canal.[24] Kahn et al. investigated the efficacy of six methods of sealer placement using clear plastic blocks with simulated curved canals. They concluded that the lentulo spiral and the Max-iProbe Delivery System were the most effective means of sealer placement, followed by ultrasonic and sonic files, and the least effective methods were the paper point and the K file.negative control groups.

However, as the master gutta-percha coating technique had produced the lowest microleakage values, it would be suggested to be used for better results. The master gutta-percha coating technique is the simplest method among the three methods tested and it requires no additional instruments and procedures. This will also reduce the risk of possible cross infection. Further research perhaps is needed to study the effect of different sealer placement methods with different obturation techniques.

\section{Conclusion}


Comparative evaluation of effects of various sealer placement techniques on sealing ability.

Within the limitation, this study compared four techniques.Out of the four techniques namely K-file, manual lentulo spiral,rotary lentulo spiral,and master gutta percha cone, showed abetter seal, with least leakage value.

\section{References}

[1]. Lai CC, Huang FM, Yang HW, Chan Y, Huang MS, Chou MY, et al.Antimicrobial activity of four root canal sealers against endodonticpathogens. Clin Oral Investig 2001;5:236-9.

[2]. Gomes BP, Pedroso JA, Jacinto RC, Vianna ME, Ferraz CC, Zaia AA, et al. In vitro evaluation of the antimicrobial activity of five root canalsealers. Braz Dent J 2004;15:30-5.

[3]. Baumgartner G, Zehnder M, Paque F. Enterococcus faecalis type strainleakage through root canals filled with gutta-percha/AH Plus or Resilon/Epiphany. J Endod 2007;33:45-7.

[4]. Yucel A, Guler E, Guler A. Bacterial penetration after obturation with fourdifferent root canal sealers. J Endod 2006;32:890-3.

[5]. Miglani R, Shankar, Indira R, Ramachandran S. An in vitro evaluation of calcium hydroxide root canal sealers and its effect on six microorganisms. J Conserv Dent 2007;10:99-103.

[6]. Kontakiotis EG, Wu MK, Wesselink PR. Effect of sealer thickness on long-term sealing ability: A 2-year follow-up study. Int Endod J 1997; 30:307-12.

[7]. Eguchi DE, Peters DD, Hollinger JO, Lorton LA. Comparison of the area

[8]. of the canal space occupied by gutta-percha following four gutta-percha

[9]. obturation techniques using Procosol sealer. J Endod 1985;11:166-75.

[10]. De Deus GA, Martins F, Lima AC, Gurgel-Filho ED, Maniglia CF, Coutinho-Filho T. Analysis of the film thickness of a root canal sealer following three obturation techniques. Pesqui Odontol Bras 2003; 17:119-25.

[11]. Farea M, Abdulqawee R, Husein A, Masud S, Pameijer CH. Evaluation of Gutta-Percha-Filled Areas in Root Canals after Filling by Two Different Obturation Techniques. Aust J B A S 2011;8:631-6.

[12]. Georgopoulou MK, Wu K, Nikolaou A, Wesselink PR. Effect of thickness on the sealing ability of some root canal sealers. Oral Surg Oral Med Oral Pathol Oral Radiol Endod 1995;80:338-44.

[13]. Wu MK, Ozok AR, Wesselink PR. Sealer distribution in root canals obturated by three techniques. Int Endod J 2000;33:340-5.

[14]. Georgopopoulou MK, M-K WU, Nikolaou A, Wesselink PR. Effect of thickness on the sealing ability of some root canal sealers. Oral Surg Oral Med Oral Pathol 1995;80:338-44. 